\title{
Editor's Reflection on the Indigenous and Trans-Systemic Knowledge Systems Issue
}

\section{Lori Bradford}

As editor of the Engaged Scholar Journal, I, along with our generous reviewers, have been privileged with reading a variety of submitted articles over the last year. In these manuscripts, authors penned their knowledge and experiences of engaged scholarship with the hope that their work would appear in an upcoming issue. I get to experience the authors' joy when the manuscripts are accepted and shared with a community who will take up those learnings and build on them. I feel pride because our scholarship is dynamic, evolving, and synergistic.

As I read the submissions for this particular issue, I recognized my much deeper responsibilities as a well-educated, cis-gendered, white settler Canadian woman sitting in this editorial role. I am reminded that a larger societal shift is happening at this time; more countries are signing on to the United Nations Declaration

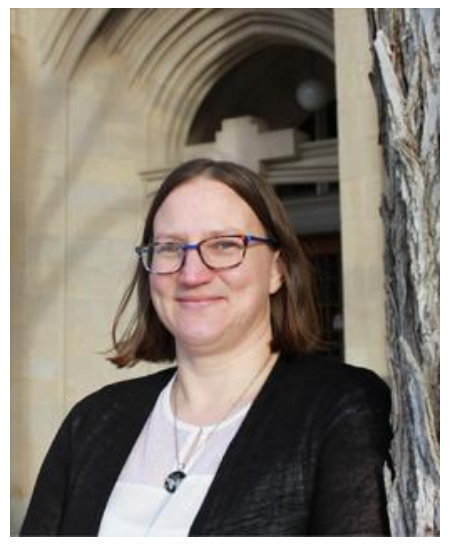

Lori Bradford

Image credit: Victoria Schramm on the Rights of Indigenous Peoples (UNDRIP). Even so, there are deeper questions, such as how UNDRIP, as a tool, is already being manipulated; whether adopting UNDRIP in some locations would constitute a step backwards; and whether adopting it, and other agreements like it, is ultimately a form of tokenism that will not compel restorative actions? Without enough Indigenous expertise in UNDRIP conversations globally, expertise shared so generously by the authors that contribute to this special issue, people privileged with white settlerhood, like me, don't know what we don't know about Indigenous lives. In this special guest edited issue, I initially relegated myself to quality control, to reader, to learner, thinking that it was not my place to regulate any part of this issue. And yet, Drs. Marie Battiste and Sákéj Henderson invited me in. They told me they wanted my voice, my experience, my language represented here too - as a trans-systemic contribution. If only all of us could convey that kind of mutualism. I challenge all of us to do so - and I share some ways how at the end of this reflection.

I have a duty, as the leader and decision-maker for ESJ, to ensure that the institution of publication that we belong to is more responsive for all. It is not enough to integrate (oh that word!) Indigenous Knowledge into ESJ's conventional form. In fact, it would be colonizing. That is why we came to decide on redesigning the whole issue. From the start, Marie and 
Sákéj drove the processes for this issue. They customized the guidelines for peer review, which was something we had never done at ESJ. We also removed the Western formatting: our cover art would normally be picked from a selection of Canadian artists, overlaid with titles, dates, and hints at contents, and background coloured how I saw fit. Instead, we hired a young Métis woman, Ms. Kennedy Halcro, who is an artist and educator from Saskatoon, to design the layout. We also left my words to the end, so as not to front-load the issue with a Western perspective. In my reflection, I try to model allyship instead of Editorial power. Here, rather than priming readers on what I think they will find valuable, I share what I learned. In compiling this issue, I:

1. Experienced a pluriverse of teachings, as Koller and Rasmussen put forward. I learned how Indigenous Knowledge is ignored by many landbased learning pedagogues. I did not know what I did not know about this, but the authors modelled how to be honest about the limitations of my knowledge so I can improve learning for all, regardless of the context. In doing so, I confronted truths, narratives, and silences that were missing in my formal education, yet are required for our continued adaptation to a changing world. These missing stories are made vitally clear by McDermott and her colleagues. In the Exchanges section, Sa'ke'j and Leroy Little Bear give us insights into maneuvering around Eurocentric worldviews. I had not considered the many ways Indigenous colleagues did so before. As a result, I commit to honesty about what I have ignored in the past, and I commit to including multiple perspectives in my teaching and research practices from now on. I commit to inviting Indigenous peer review on my courses and manuscripts, at a time and in a way that is led by the reviewer, not me.

2. Learned, through Cajete's elegant teaching, that Native American culturally harmonized education has evolved around the problem of embracing how to do something in a way you have not done it before. He exemplifies that challenge with a graphic illustrating the curriculum process for Native American students. That figure counters the idea that education ought to be designed by self-defined experts conveying theoretical preparations for future situations that may occur in students' life or work experience. This resonated with me as a social scientist. I'm becoming more concerned with modeling to students that they may not know what they don't know; modeling who to ask and how and where to look for unknowns; and showing them how to practice reflexivity. I want my students to feel comfortable being uncomfortable in their self-appraisals, rather than making students memorize chapters of textbooks. I commit to teaching more about noticing ourselves and about the different hows of doing research and being in the classroom. 
3. Learned that language is knowledge and learning a language is, as put by Whiskeyjack and Napier, reclaiming sovereignty, ceremony, and balance. I also need to learn to take my turn, as Inglis points out. To be a better ally, I commit to enrolling in an Indigenous language course in the Fall semester, and to encourage others to do the same. I commit to listening using all my senses.

I have a story to share about an incomplete act of allyship and doing better. With colleagues Lalita Bharadwaj and Karl-Erich Lindenschmidt, I published a paper in Society \& Natural Resources in 2016 revealing that a number of major journals for natural resource management put up barriers to community members publishing their work. The paper grew out of multiple rejections one author had received when submitting papers with northern Indigenous individuals and groups as co-authors. We surveyed 11 natural resource management journal editors for their views on community-based scholars and citizen scientists being recognized as authors, and then built a typology from those results. It was disappointing how few of those editors could suggest a way that these authors could be included. Most said they should simply be listed in the acknowledgments section of the published papers, which, as a response, conflicted with international conventions of scientific authorship. While we provided alternatives and recommendations in the paper, I can now see how important it is for me to follow up and hold those journals/editors accountable to decolonizing their venues. Now that I have been the recipient of so much knowledge from this issue, I realize that other editors, like me, just don't know what they don't know when it comes to Indigenous Knowledge systems and insights. I commit to repeating that study, now that it is five years later, to monitor advances, applaud and raise awareness about venues that are adapting, and hold accountable those that have not even started conversations on their decolonization. I commit to doing this work with Indigenous colleagues so that they are listened to.

I have also learned some strategies for allyship from the papers in this special issue and from interacting with guest editors, authors, and peer reviewers in email exchanges and phone conversations. ESJ's community of reviewers gave us insights on the recursive process that occurs in the trans-systemic space, as the Indigenous ideas and thinking build, weave, blend, and contrast with Western Science, which in turn creates new ways of thinking about engaging with Indigenous communities. Through these interactions, ESJ's community breaks down barriers by enacting the lessons in this issue. First, we do so by listening to Indigenous people. The front cover's syllabics translate to "Listen to Us" and I hope all our readers will be open to the knowledge shared in this issue. Second, we overcome barriers in our own thinking by recognizing privileges. Practice listing your privileges. Do so out loud when introducing yourself, in papers, in class, or in the field, so others can help you recognize if there are privileges you are missing in your engaged scholarship, teaching, and practice. Say them out loud so your students and partners have a model to follow. Third, in this issue Kelly teaches us to honour the diversity of knowledge systems, and to do so by deliberately expanding the ones you rely on for your work. The benefits that accrue from being led to new ways of knowing improve the 
lives of individuals and ultimately increase ethical actions in society, such as global evolution in the implementation and ethical adaptation of UNDRIP towards benefitting Indigenous peoples. I will honour the diversity of knowledge systems by giving Indigenous and transsystemic systems more time and attention, regularly. I will use sites like www.citeblackauthors. com to find authors I would not generally find on mainstream databases. I will use inclusive syllabus checkers, like that of Kim Case found at https:www.drkimcase.com/resources/, to make regular adjustments to my teaching practices. I also ask our readers to invest time and money into having Indigenous peer review of engaged scholarship. Another suggestion is to take time to learn a few words and their pronunciation related to your engaged scholarship in an Indigenous language, then learn how to use those words meaningfully in your research, scholarly, and artistic works and teaching. We can each take these small steps. I encourage white settler readers to take these steps, and I will report on my progress in the coming issues, as well.

I'm deeply grateful to the guest editors, Drs. Marie Battiste and Sákéj Henderson, for their teachings during the editorial processes and building of this issue. I'm deeply grateful to all those who contributed knowledge, who reviewed and shaped that knowledge for our readers, and who continue to share knowledge out there which may not be represented in these works, but is dynamic and evolving, just as we hope we are here at ESJ. I am also deeply grateful to our readers for your feedback. Please feel welcomed to email me at editor@esj.usask.ca to provide me with your advice and concerns. Thank you. 